\title{
Obituary - Dr. Hans J. Muhs
}

\author{
(1939-2021)
}

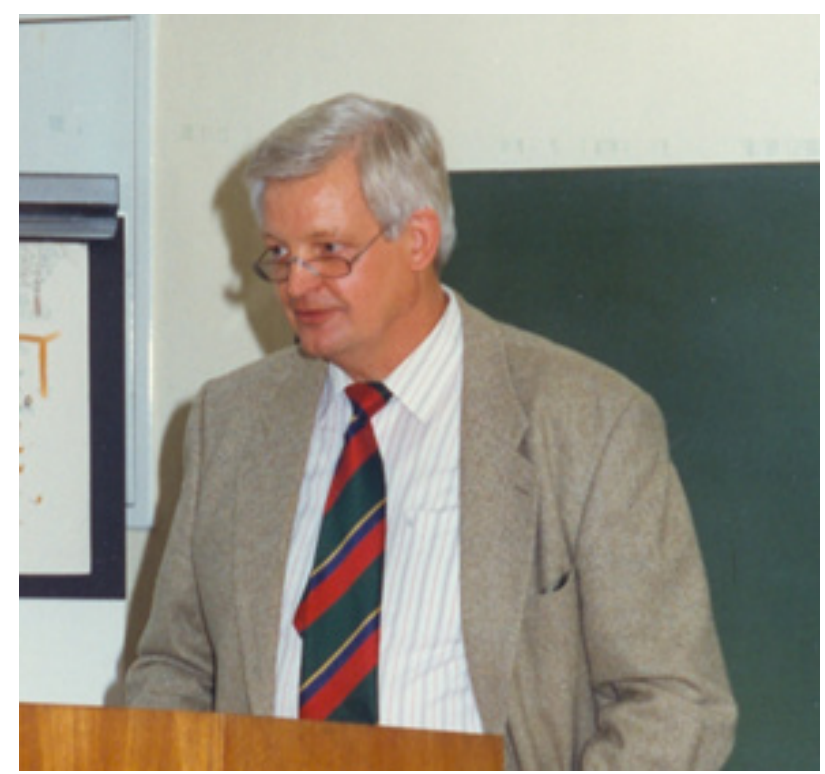

Dr. Hans-J. Muhs passed away on July 20, 2021 in Kleve, Germany. He was head of the Institute of Forest Genetics ("Institut für Forstgenetik", of the formerly Federal Research Centre of Forestry and Forest Products - BFH -, today part of the Thünen-Institute) in Grosshansdorf, Germany, from 1989-2004. He was born on February 14, 1939 in Alt-Mühlendorf/Warder, SchleswigHolstein, Germany. He earned his Diploma degree in Wood Science at the University of Hamburg (1968) and received a prize from the Freiburg Forest Faculty for his PhD-thesis "Investigation of the population structures of different selection lines of Drosophila melanogaster using isozymes". In 1976, he made his habilitation in the area of Forest Genetics and Forest Tree Breeding. The work was supervised first by Klaus Stern at the Institute of Forest Genetics and Forest Tree Breeding (BFH - Institut für Forstgenetik) at Grosshansdorf, Germany, and then under Hans Marquardt at the Forest Botanical Institute, Forest Faculty of Freiburg, Germany (1976). He served first as Deputy Director of the BFH - Institut für Forstgenetik (1976-1989) and later as Director until his retirement (2004). During the time as Director of the institute, he was editor in chief of the journal Silvae Genetica.

Dr. Muhs started his scientific career with the methodology of isozyme separation and interpretation of gene loci on Drosophila melanogaster, which he then transferred to forest tree species. These biochemical methods turned out to be a powerful tool in forest genetics and tree breeding in the 1970ies and 1980ies. He also continued the work initiated in the 1950ies on hybrid breeding of European aspen (Populus tremula L.) and American aspen ( $P$. tremuloides Michx.) and obtained the approval of two hybrid aspen-offsprings and one clone mix in the category "tested" for commercial use. Later, his interests changed to the genetic structure of forest tree species, especially provenance studies of European Beech (Fagus sylvatica L.). He established several international series of beech provenance trials and initiated additional series after 1990 in the eastern part of the distribution area. More than 400 provenances originating from the whole area of distribution were tested on over 70 field-testing sites located throughout the range of beech. The International Union of Forest Research Organizations (IUFRO) helped in collecting the numerous seed samples and in establishment of the field sites. With beginning of the 1990ies, he established the work area of tree biotechnology, including in vitro culture and gene technology. Here, he focussed on risks and potentials of genetically modified trees (GMOs). He initiated the first field trials with genetically modified poplar in Germany. During his scientific career, he published more than 100 papers.

Dr. Muhs was very much involved in the development and international standardisation of laws and regulation of forest reproductive material. As consultant to the national government, the EU Commission, and the OECD, he contributed to a fundamental revision of the rules for the marketing of forest reproductive material. Progress in the procurement, production, and widening of the species spectrum of forest 
reproductive material as well as new methods of cloning by in vitro culture as a prerequisite for genetic modifications, all required a comprehensive revision of the rules. As well, he initiated work on the development of new technologies for wood identification as prerequisite to detect timber derived from illegal logging. This original work was fundamental for ongoing activities of the Thünen Centre of Competence on the Origin of Timber. After intensive work and over 12 sessions, a majority of countries adopted the completely revised draft of the OECD Scheme. The revision of the OECD Scheme would not have been possible without the contacts provided by IUFRO.

Dr. Muhs contributed to IUFRO for 30 years. He co-chaired IUFRO WP S2.04-05 on "Biochemical Genetics", (1973-1986), founded, coordinated and participated in two IUFRO units - the Interdivisional WP S2.10.00 on "Improvement and Silviculture of Beech" (1984-1996) and WP S2.03-14 on "Legislation on Forest Reproductive Material" (1985-2004). He organized and supported numerous IUFRO workshops and meetings in these fields and in 1995, he received the IUFRO Certificate of Appreciation. In 2004 he received the IUFRO DSA in 2004 for his longterm contribution into IUFRO advances in biochemical genetics, improvement and silviculture of beech, and on legislation on forest reproductive material.

Bernd Degen and Matthias Fladung

Thuenen Institute of Forest Genetics, Grosshansdorf, Germany

\section{Personal sources:}

Muhs H.-J. Personal communications (October-November 2019) via Dr. Georg von Wühlisch

Professor Dr. Dr. h.c. mult. Walter Liese, personal communication 